\title{
The Impact of Cross-Cultural Communication on Foreign Managers' Leadership Style in China-Based International Organization
}

\author{
Ying Ao \\ Chengdu University, Chengdu, China \\ Email: mlbsabc@sina.com
}

How to cite this paper: Ao, Y. (2016) The Impact of Cross-Cultural Communication on Foreign Managers' Leadership Style in ChinaBased International Organization. Open Journal of Social Sciences, 4, 99-118. http://dx.doi.org/10.4236/jss.2016.49010

Received: August 12, 2016

Accepted: September 18, 2016

Published: September 21, 2016

Copyright $\odot 2016$ by author and Scientific Research Publishing Inc. This work is licensed under the Creative Commons Attribution International License (CC BY 4.0).

http://creativecommons.org/licenses/by/4.0/

\begin{abstract}
In order to make a clear identification about which leadership style can be appropriate and effective for foreign leaders in China, a specific focus has put on the Chinese natives' cultural values and its influence on foreign manager's leadership styles. Six foreign leaders from two China-based international organizations in Chengdu and Shenzhen were interviewed on several issues, including decision-making, conflict management and work distribution. A qualitative analysis has been conducted through theme categorization which responds that transformational leadership style can be effective and appropriate for foreign leaders to strengthen their relationship with Chinese employees.
\end{abstract}

\section{Keywords}

Cross-Cultural Communication, Leadership, Transformational Leadership, Expatriate Leaders in China

\section{Introduction}

Along with the gradual removal of trade barriers as well as cross-border barriers around the globe, business expands speedily on a global scale, especially selectively flooding into the fast-growing developing countries, in order to exploit more opportunities in the international market. According to Habib-Mintz's article, "MNCs and developing countries are intertwined with political and economic relationships of convenience" [1]. After implementing economic reform and the open-up policy in the late 1970s, and then accessing into the WTO in the year 2001, China gradually became one of the important foreign investment destinations for international corporations, and about 90 percent of the world's top 500 companies have invested in China [2]. Such kind of situation tends to make the local culture diversified and offers a large amount of 
chances for intercultural interaction both within and out of the organization. However, although there is a large amount of international corporations in China, not all of them have the ideal market development. Many foreign managers "have often reported frustration and confusion", when they do business in China [3]. Thus, this will undoubtedly exert some conscious and unconscious pressures on both the foreign leaders and Chinese native leaders due to the potential seeds of cultural conflicts and misunderstandings caused by localization and regionalization in the cross-border alliances. Moreover, this will cause the failure in completing foreign leaders' assignment in China because they will be confronted with difficulties such as lack of knowledge about culture in host country and different cultural perceptions about leadership effectiveness [4]. Therefore, it is essential for foreign leaders to meditate what kinds of the leadership style are effective and accepted by their colleagues to deal with this cross-cultural barrier.

In some of the studies, researchers present that concerning the effective leaders' behavior across culture, some valid similarities and principles in leadership style that transcend cultures are necessary for the global leaders [5]. Thus, from their point of view, there might be a trend in leadership universality [6]. On the other side, many researchers argue that the application of leadership styles may differ due to the influence of different cultures [7]. However, in spite of considerable research conducted on leadership style effectiveness and differences in various countries in recent years, there is seldom research focusing on the impact of host countries' culture values on foreign managers' leadership style [8].

Therefore, according to the cultural dimension put forward by Hofstede and the theories of leadership frameworks proposed by some scholars, the purpose of this research is to put a specific focus on the influence of Chinese cultural values on foreign manager's leadership styles so as to explore the cultural explanations behind cross-cultural management communication between foreign leaders and Chinese employees. At the same time, the research supposes to make a clear identification about which leadership style can be appropriate and effective for foreign leaders in China.

To investigate on this issue has two main reasons. On one side, good cross-cultural management communication between foreign leader and local worker is one of the basic factors leading to successful management. That is, a leader who grasps these skills can have the ability to decrease turnover rate of employees, motivate their followers to make remarkable performance in managerial mission, and create a pleasant working environment [9]. On the other side, if we can explore effective and accepted leadership style for foreign leaders in China, they can be more professional in controlling communication conflict so as to enhance their leadership competence [10]. In general, the results of this research will have some values and implications for both the foreign leaders who come to China and try to make things work there and Chinese leaders who want to integrate different cultures into best leadership practices.

\section{Literature Review}

In order to get a better understanding of the relevance of different intercultural com- 
munication values and its influence on the leadership, first of all, this research explores the literatures on major cultures constructs. After that, it reviews the literatures on leadership style and its relationship with culture, especially focusing on the culture and the currently prevalent transformational leadership. Indeed, from the cultural sight, it may examine the easily ignored aspects of leadership which include the cultural shaped behaviors and styles that influence the effectiveness of leadership [11].

\subsection{Understanding Culture Values}

Culture values have a general impact on the implement of the international manager's leadership [12]. To get a more specific understanding of how culture influences the practice of leadership, it is necessary to make a clear understanding of culture value. In respond to the increased research attention on the complicated characteristic of culture value and the relationship between cultural differences and leadership, Hofstede's classic study of culture has become a gradually important framework [13]-[15]. According to the Hofested's theory, there are five main dimensions: the first dimension is power distance which refers to the degree of accepting the power inequality in the society. Then, uncertainty avoidance is the extent to which the certain group of people endures the unknown issues. The third dimension, individualism-collectivism aims to investigate how people keep the relation of the interest between individual and group. The fourth one, masculinity-femininity evaluates the gender orientation in the organization. At last, in order to explore the culture in Asian countries, here is long-term orientation which stands for most of the Confucian philosophies in Chinese traditional values [16] [17].

To some extent, Hofstede's culture dimensions is one of the well-known ways to clarify the culture differences on the national level and has the value to enhance the cultural cognition for the leaders who are working in the cross-cultural context [14] [15]. However, there are still some criticisms for this cultural dimension. Dorfman and Howell, for example, argue that this culture framework has been done by only two surveys with IBM which has the limitation in the ability to include other organizations [18]. Moreover, Maznevski criticizes it by adding a serious issue that two of the dimensions and many of the items within dimensions seem to be separated and unrelated [19]. However, despite these criticisms about Hofstede's theory, these cultural dimensions seem to provide validity and trustworthiness to the management studies.

\subsection{Cross-Culture and Leadership}

There are many definitions about leadership, but most of them have the conception that leadership is relevant to the "interaction between the leader, the follower, and the situation" [20]. That is, one leadership style or behavior will be accepted by the followers in one culture, but it can be regarded as inappropriate in another [21]. Therefore, it is necessary to consider a theoretical model which can illustrate the influence process for leadership under the cross-cultural situation [21]. The cross-cultural model of leadership conducted by a few of researchers exactly indicates that culture has an encom- 
passing impact on leadership process including leader's image, individual and group processes, and substitutes for leadership [21]-[23]. Ah Chong and Thomas clarifies the cultural influence on the expected leader's behavior by giving an example that Pacific Islanders expect leaders to give specific instructions, but the same behavior is not required for an ideal leader in Anglo-European culture [24]. Similarly, Thomas shows that in the high power distance culture the paternalistic leadership are more likely to be accepted than in lower one [13]. In addition, Dorfman indicates that since culture can be treated as invisible element that determines the nature of the situational features which will act as effective substitute for leadership [22]. Moreover, the evaluation of leadership effectiveness is also subject to cultural influence [13]. For example, the leader's performance that does not focus on the group harmony and interest will be considered as negative and ineffective in the collectivist culture [22].

However, although this model reflects a clear frame for the relationship between culture and leadership, some theorists argue that it does not explain how to manage the interaction between the expatriate leader and the local followers. Thus, some scholars (e.g. Peterson, Brannen, and Simth, Ah Chong and Thomas) have done the research to address this matter for leaders who do not familiarize with the cross culture workforce by giving two important hints [25]. One is that the followers' expectations on the leadership are mainly based on the leaders' culture background. The other is that too much adaptation of the behaviors in the followers' culture will lead to ineffective leadership for the foreign leaders.

Nevertheless, notwithstanding either the limitation in the model or the insufficient evidence in the later work, all these literatures can provide the logical conclusion that because of the increasing need for having competent global leaders in workplace, it is essential for the managers, especially those who are assigned to foreign countries, to pay more attention on selecting the appropriate leadership style so as to have a successful leadership practice in different cultural situation [26]-[28].

\subsection{Culture and Transformational Leadership}

Considering about the demand for the capable leaders with effective leadership to work across different countries, many scholars, like Yukl, suggest the value of the recent transformational leadership [21]. Similarly, Bass and Avolio indicates that transformational leadership which includes the well-known four leadership aspects: idealized influence, inspirational motivation, intellectual stimulation and individualized consideration, is an effective and ideal leadership style since it emphasizes the process that leaders influence followers by transforming their attitudes, beliefs and values to facilitate their motivation [29] [30]. According to the cultural-universal perspective supported by some scholars, specific aspects of transformational leadership are universally accepted across cultures around the world [6] [31] [32]. This kind of perspective implies that due to the common demands from the global organization, the leadership practice tends to be more similar than different. Thus in terms of this perspective, transformational leadership style has some common qualities under the influence of different cultural 
background. For example, the GLOBE study has found that some leadership behaviors in transformational leadership are universally endorsed across widely varying cultures [31].

On the contrary, another recent set of studies present the notion that culture values dimensions influence how transformational leadership is conducted and perceived form country to country [33]. Depending on the culture, the transformational leadership will be more effective within less traditionally entrenched cultures, such as in some Western countries, while it would have less positive impact in countries with traditional cultures, such as China, where the culture are characterized as high power distance so that the respect for hierarchical features and conformism are reinforced which to some extent will impede the development of transformational leadership [34]. On the other hand, however, unlike the findings from this research pertaining to China, in the study conducted by Jung, Yammarino and Lee, transformational leadership are perceived to be more useful in collectivist culture than in individualistic one [35]. It seems to be more prone to enhance the followers' motivation to work for group goals instead of self-interests in collectivistic cultures, such as in China.

In general, no matter cultural universal perspective or cultural specific one, they all aim to explore the influence of culture on transformational leadership and try to testify its effectiveness for leaders by identifying and comparing transformational leadership patterns in different countries [36] [37]. Thus, the overall review at these literatures reflects that very little research has been undertaken to investigate the area of the influence of host country's cultural values on expatriate foreign leaders' leadership style. Therefore, in order to examine this issue, this research put a specific focus on the foreign leaders in China-based international organization so as to address the research question of, what kind of leadership style do foreign leaders effectively espouse under the influence of Chinese cultures?

\section{Methodology}

Before carrying out a comprehensive analysis and discussion in the research, some space should be devoted to describing the methodology. In this research, semi-structured interviews, a commonly used method in intercultural communication research, is employed to explore foreign expatriate leaders' leadership style under the impact of Chinese cultural values in a China-based international organization. The methodology of interview research is mainly related to the criteria of research participant selection, the method to collect data, the principles of research instrument design as well as the procedure of data analysis.

\subsection{Overview of Semi-Structured Interview}

Unlike the aim of quantitative approach which emphasizes on doing survey, the purpose of qualitative interview is to offer unique perspective and original explanations rather than underlining the predictions of relationships [38]. What is more, in spite of the large number of observations and easily comparable information provided by the 
quantitative survey, it can only focus on the surface of values and practices in these organizations. However, although compared with quantitative survey, the number of observation in qualitative interview is low; several aspects of organizational area can be analyzed so as to provide thick description. That is, on one hand, it is really a great chance to gain a more accurate and clear picture of these leaders' perspective and behaviors [39]. This is possible due to the open-ended questions and flexibility to answer according to their own thinking since there is no constrained choices for answers. On the other hand, for the ambiguous question, qualitative interview can be used to make a clarified explanation about these questions immediately [39].

Further, in the qualitative interview, there are three types of interview, namely structured interview, unstructured interview and semi-structured interview. Compared with the structured interview style and unstructured one, the semi-structured interview, which has been done according to the prepared question list and schedule, is likely to provide more room to explore profound information since it is more flexible [40]. Thus, as semi-structured interview questions are not highly standardized, this method of data collection can encourage participants to tell more about their own opinions which can be highly suitable and collaborative for this type of study since it matches the purpose very well [38].

\subsection{Participants}

The participants in this research are six foreign leaders from Western countries who are now working in China-based international organizations for average four years. In order to protect the participants' identities, researcher uses the pseudonyms to represent each participant. The leaders who are the typical representatives for the business development in China are selected from two international organizations. Two (Boris and Zeal) of them are expatriate principals in an international school in Chinese city, Chengdu. The other four (Howell, Sean, Susan, and Ivy) are managers in a design international corporation in Chinese city, Shenzheng. The criteria of participant selection are mainly based on their working experience in international team, their position in that organization and their willingness to accept this research project. The top level managers always have more opportunities to make the important decisions and strategies, allocate task on behalf of the whole organization to subordinates as well as cooperate with different teams both within and out of the organization. Considering about this, all the participants in this research are those who hold senior level managerial position in the organization. In addition, the reason why these foreign expatriate leaders all have the average four years' working experience in China is considered, because long working time in China would enable better acceptance and understanding of Chinese culture among them, calling some adaptive changes in value and behaviors, which can be helpful for their consideration of effective leadership choice. Thus, this aspect may strengthen the purpose of this study.

\subsection{Data Collection}

Generally speaking, this research took several steps to collect data from those leaders in 
the China-based international organizations. First of all, the researcher had to have an overall understanding of background of leaders and organizations so as to gain a basic idea of how to ask the interview questions effectively. Then, the researcher had to make contact with the participants to briefly introduce the research to them and to make sure that they were willing to participate. When these participants indicated their interest in the research, the researcher arranged for the qualitative interviews to be conducted via the Internet (e.g., Skype).

Since this is a semi-structured interview, the questions in it are all open ended one which are related to the research aim and objectives. According to the research question that seeks to investigate the kind of leadership style which foreign expatriate leaders effectively espouse under the influence of Chinese cultures, the interview questions (Appendix 1) are designed from three main aspects. The first section of open questions talks about the managers' duty and daily work in the organization, and their communication style with subordinates, especially how they deal with conflict in the specific situation. This set of questions provides a general understanding of the interviewee's situation and give us some information about these leaders' communication style in relationship construction. The second part of questions is related to work distribution and decision-making. That is, when these leaders assign task and make decision, how do they contact with their employees to accept that work and how the make the decision. To some extent, the answers from this kind of questions illustrate the degree of power control for these leaders. Then, the third series of questions has focused on their own preferred leadership style. In these questions, the interviewees are expected to define leadership from their point of view and to state out how they lead their employees. Thus, the answers from interviewees can be used to describe their leadership style. All questions which have been asked during the interview are based on Putnam and Wilson's Organizational Conflict Communication Instrument and Bass and Hofstede's Multifactor Leadership Questionnaire [41]. In this way, we can combine some scholar's theory to sufficiently analyze the data and information which collected from the research.

Simply because these participants may not only do their business in China but also have business trip around the world, having interview via internet is the only a feasible way to communicate with the participants. Using this method, there is a limitation. That is, during the interview, there may be some noises, like network instability, interruption and language barriers. To some extent, it may influence the interview's quality. However, compared with sending email, this method is much better, because at least the participants' emotion, body language and communication behavior can be observed and this can make more contribution to the discussion.

\subsection{Data Analysis}

After effectively organizing the interview process and collecting data, all the information should be analyzed. In terms of the data analysis, the thematic analysis of the interpretive approach has been utilized to discuss the issue. During the process of data 
analysis, the information collected from interview has been read again and again so as to locate the themes and assign initial codes or labels to condense the mass of raw data. Further, the second step was to conduct axial coding [42]. That is, the initial themes emerging from the first step were reviewed and examined by investigating causes and consequences; conditions and interactions, and then looking for categories or similar concepts, so as to develop a structure to analyze the collected information. In this exercise, theme refers to particularly related words, items, concepts and experiences. To be a theme two criteria had to apply. One referred to the answers from interviewees tending to share the same or similar opinions. The other one referred to some frequently mentioned keywords which were related to the questions [43]. Thus, in this semi-structured interview, it is necessary to compare all the interviews so as to find out the themes consisted of similar values, beliefs and events mentioned by these leaders. The processed data was finally sorted into various categories indicating the leadership styles that expatriate leaders favored. Additionally, after that, in order to get a constructive conclusion of the research, qualitative information from interview has been analyzed through the combination with some of the cultural dimensions and leadership theories which have been mentioned in literature review.

\section{Research Findings}

In this section, the results which come out through the qualitative interview will be revealed so as to respond the research question. In the following part, the preferred leadership characteristics of foreign leaders in China will be identified in order to provide some irradiative insight for either foreign leaders or Chinese leaders and for further study on cultural influence of leadership.

For Western leaders who want to continue doing their business well in China, they should be aware of integrating the foreign leaders' leadership qualities with Chinese culture organically and systematically since having things done in a way that satisfies the Chinese is a major source of success in China. According to the interview with these foreign leaders in China-based international organizations, there are some leadership behaviors that these leaders present in the cross-cultural context. Among these leadership behaviors, five typical leadership practices have been highlighted by these Western leaders, which they combine with Chinese thinking, given the importance of culture reasons.

\subsection{Establishing Mutual Agreement with Adequate Empowerment}

Compared with some state-owned organization in China which has various rules and regulations, these China-based international organizations are more flexible. In addition, because of the different cultural influence between Eastern and Western countries, there will be different management concepts among them. Hence, when foreign supervisor and local subordinates work together, it is important for the foreign leaders to help Chinese employees make sense of task through communication. Although under the influence of Chinese culture, such as Confucian doctrine, Chinese employees show 
their respect for authority by obeying what the managers say, all the foreign leaders in interview, however, still emphasize that the consensus with the local subordinates is a crucial factor to lead the company successfully in China since it is a way to establish mutual respect which in turn is a core value in Chinese culture to establish long-term relationship. A foreign principal, Zeal, in this interview indicates that

Hierarchy is a common phenomenon in China, so some Chinese workers hardly speak up their disagreement in the meeting. But I'd like to say, I am a leader not a dictator, so many times when the decision about teaching goals remained to be consulted; I often created an open atmosphere and ask for opinions from local staff to make a consensus plan.

Similarly, the foreign leader, Howell, in the design corporation has stressed that

"I know Chinese people are used to having a power distance, but I have never used my power to order on my Chinese employees without communication. Many times, a project and a goal for a task, I think, needs discussion so that finally we can achieve mutual agreement on the plan which can produce desired and even better outcome. This is particularly true for foreign leaders doing business in China, because this is a respectful leading style to build mutual trust."

Further, the importance of empowerment is a vital aspect which Western leadership always emphasizes in leading a team and stimulating potential and value from employees. Therefore, when Western leaders come to work in China, they always carry out their leadership with empowerment after reaching agreement. However, espousing large extent of power distance between superior and subordinates, Chinese employees sometimes are reluctant to accept empowerment due to the influence of values in Confucianism, such as keeping order and respecting authority and their fear of being blamed for the failure. Thus, in order to make Chinese employees feel the importance and necessity of empowerment, foreign leaders cannot simply import the concept of this Western leadership quality into China and expect it to work (Howell, Zeal, and Ivy). The foreign leaders illustrate this perspective as below.

"I'd like to empower my subordinates when we reach agreement on our plan. I have to say, implementing the empowerment culture is necessary in China, but honestly, it is more complicated. The significant point here I want to say is that we should provide guidance for Chinese employees after empowerment. It is best for the leaders to make sure that the employees are on the track and to see how things progress."(Howell)

"After reaching consensus, I have to underlie the empowerment. Actually, it is not as easily achieved in China as in the West. If we want to make it work, what we should do is to modify before we apply it in China. I mean it is better to use delegation rather than empowerment in China. Chinese employees are more comfortable with delegation, because they have power and responsibility to do the work, but don't have to bear the negative result." (Ivy) 


\subsection{Encouraging Risk-Taking and Innovation}

Generally speaking, Westerners always lay the more stress on taking a risk and being creative. From their point of view, people who "keep on the rail" are regarded to be conventional and are not sought out by leading-edge firms due to the less competitive strength in innovation. On the contrary, traditionally, the Chinese are often reluctant to take risk and thus finally fail to be innovative. The reason that Chinese employees are unwilling to take risk is due to their lack of motivation. Thus, stimulating Chinese employees' motivation is a way that foreign leaders always adapt to improve their willingness of risk-taking and being innovative. Some foreign leaders say that in order to stimulate the employees' motivation, they have provided challenging new projects and activities:

"After being the principal in this international school, I support my Chinese teachers in trying new teaching approaches. Based on my observation, the Chinese teachers are not creative enough. So I always try to find an appropriate time to assign new assignment to them." (Zeal)

"In our company, creative is a core value. So I assign them (Chinese employees) task that are beyond their current comfort level and stimulate them to find new way to succeed. New challenge, new approach, new assignment is worth a try!" (Howell)

In addition, although the leaders stimulate the employees' motivation to take risk, it still may not have effect on some Chinese employees. To some degree, this can be attributed to the large extent of uncertainty avoidance in Chinese culture. To be specific, there are multiple rules and regulations for people doing business in China so as to avoid some unexpected business issues. Hence, the Chinese are afraid of taking risk since they will be punished by these rules for making any mistake during the process of taking risk. Under such circumstance, on one hand, it is necessary for the leaders to emphasize that employees do not need to undertake the negative result if they take risk and try to be creative (Boris, Susan, Ivy, Howell). For example, the principal Boris and manager Howell stress that,

"I prefer to encourage my staff to be creative during teaching process. At first, I found that the Western teachers are willing to do that, but Chinese teachers feel frustrated. When I got the feedback from Chinese teachers, I realize that they consider that it is a big risk to do so, because if they fail, they have to bear the fruit. So I reassure them that they will not be penalized for making any mistake if they were trying to be innovative." (Boris)

"No punishment, no penalty for failure, this is what I should say before I assign any challenging task to Chinese employees." (Howell)

On the other hand, after undertaking the risk task, leaders should make their employees, especially those who do their work successfully, feel self-satisfaction of taking such challenging assignment. One leader in the interview explains that

"Rewarding employees for being risk-taking is necessary. Money is important to 
employees, but it is not as important as some people think. Stimulating employee and giving them a sense of personal satisfaction can make them passionate. They can see what they have done. I believe this is the best motivation. Such feedback can encourage more people to take risk in the future work."(Ivy)

\subsection{Building Trust with Chinese Employees}

No matter in what organizations and countries trust is an indispensable factor for the leaders and other employees to work well together. Comparing with Westerners, Chinese, however, are relatively slower to trust people with whom they do not have close relationship because Chinese people with collectivistic view tends to treat stranger as less valuable and meaningful. Chinese people do not build up the trust until the behaviors that supports one's words. What is more, nowadays because of the requirement for the quick movement in business, the insufficient time makes it more difficult for the foreign leaders in China to establish the deep and strong reciprocal relationship. Therefore, in order to quickly build trust with Chinese employees, on one hand, it is necessary for the foreign leaders to be professional and capable so that they can be a role model to make Chinese employees trust their ability to lead the organization. Foreign leaders' judgment abilities to deal with Chinese teachers' teaching issues, according to principal Zeal, is an important factor to establish Chinese teacher's trust on them. Another principal (Boris) in this international school support this by emphasizing that only when foreign leaders prove their professional administrative ability, such as the capability in evaluating the Chinese teachers' teaching strategy and performance, can they gain these teachers' trust in an easy way. In addition to this, the leader, Sean and Susan, in a design corporation indicates the same meaning:

"I feel one of the important things for me here is to gain trust from my Chinese employees. I know it is a tough work. When I was a new manager in China, the common expression by my Chinese employee, I always heard, is 'lao wai'. For a long time here, I know this term does not mean my Chinese employees disrespect me, but contain the meaning of low trust. So I found what I have to do to make them trust me is to be capable. To have ability in organizing a big project is significant in our company. I think now my Chinese employees never suspect my ability, and I have built a comfortable trust relationship with them, although it is a long time with lots of give and take." (Sean)

"Employees in China respect those who have power, but they show their soul trust to those who have ability to be a role model. I have been told by my Chinese employees that they trust me on undertaking the important case because of my capability." (Susan)

On the other hand, Chinese people prefer to build deeper form of trust, personal trust, rather than the formal trust found in many Western countries. In relation to business in China, Chinese people always believe that it is better to make friends first and then do the business. Thus, for the foreign leaders in China, they can start by showing wil- 
lingness to openly talk about themselves in order to quickly build the personal trust. In the interview, Howell, the manager in the design corporation shows this point like this:

"I'm proud to have my business in China, but the issue of trust here is one that concerns me very much. In simple way I can say in West, business is above any other relationship, while in China personal relationships come before the business. So when I build up the close personal relationship, I have to gain personal trust from my employees. In order to do so, I always satisfy my Chinese employees' curiosity about my background. I tell them about my history, my family, my hometown, my educational experiences and business experiences. I mean I open myself instead of hidden myself." (Ivy)

\subsection{Leading from the Heart through Caring Approach}

There is a central component of successful business leadership for foreign leaders in China that is, leading from their heart. This is a common trait for leaders in both Western and Eastern countries. However, considering about the influence of Chinese cultural values, particularly indirectness, foreign leaders who are accustomed to be straightforward should think about how they can apply this trait effectively in regard to China. According to the leaders in the interview, they all present the importance of leading their employees from heart through the caring approach, but most of them underscore the necessity of adapting this approach to Chinese thinking.

First of all, they show their care to both public and private issues of their Chinese employees. For example, principal Zeal notes that

"I try very hard to use my heart to lead. I show my care to my employees, no matter in my country or now in China. But the difference is, in China, I need to display my care to them about not only the task-related issue, but also personal or family issues. Sometimes I feel myself to be a parent rather than a principal."(Zeal)

Then, the foreign leaders underlie the significance of showing concern on Chinese employee's emotional reaction. Compared with Westerners, Chinese people are more likely to show their emotion in an indirect way. Thus, the foreign leaders should be more sensitive to Chinese employees' reaction.

"As for Chinese employees, they always hide their true feeling and keep silent when they dissatisfy with someone. Normally I keep a long time observation in daily interaction. I will show my care and empathy to their emotional reaction if I find."(Sean)

Lastly, many leaders show their care toward employees through giving praise. In doing so, Western leaders have to be careful in China of how the praise should be given to Chinese employees due to their value of "di diao" (low-key).

"Working hard or not depend on each people. One incentive method to show my care about hard working staff is praise. But my Chinese employees told me that they feel embarrassment when I appreciate their performance in public meeting. 
They said Chinese employees can regard the praise in public as show-off. So I always express my praise to Chinese employee privately." (Howell)

\subsection{Managing Conflict with Obliging and Tender Style}

These leaders are working in the cultures which are different from theirs, so management value sometimes will be different with the Chinese employees. Thus, when disagreement appears, the conflict sometimes will be unavoidable among them. According to data collecting from these Western leaders, all the leaders in the interview imply that when they consider about the management strategy that they used to deal with the conflict with their Chinese employees, they always tend to shift their original conflict management style into the one that satisfies the Chinese concerns. That is, given the mutual-face concern and the principle of harmony in China, most of the foreign leaders in interview demonstrate that they prefer to become obliging and soft in resolving conflict in China rather than still being aggressive and competitive which they often use in Western. (Howell, Susan, Boris, Zeal)

When confronting with conflict with Chinese employee, the manager mentions that "At the board meeting, disagreement can frequently occur. If I argue with them directly, things may get worse. For me, I try to use placid attitude to solve these problems. I think it can support me to create a harmonious working atmosphere and to reduce the smell of gunpowder." (Susan)

Similarly, the principal Zeal echoes this point by saying, "Of course, conflict can be commonly observed among us. When I manage it, I need to concern about their face. I use some euphemistic way to mitigate the conflict. Usually, I need to be softer.”

These are two female leaders who are typically regarded as someone with tender and soft feature. However, in the interview, two male leaders also indicate that under the influence of desire of keeping harmonious relationship with Chinese employees, they usually conform to others to bring them into harmony by lowering themselves.

"Once, one of my Chinese members was not satisfied with my decision on a project. Another guy told me he got angry at me for making up my mind without considering about his plan. Actually, we have considered his plan for a long time, but finally we found it still has something unfeasible. So we give up his plan. The next week, I went to him and apologized for making him upset. I know Chinese people always concern mutual face, mutual relationship. So in this issue, I think it is necessary to lower myself. It is one of things that I can learn in China." (Howell)

To sum up, we can find five leadership styles in the interview that these Western leaders combine with Chinese cultures. These styles indicate that when Western leaders do their work in China, they should try to establish mutual agreement and then decentralize the power to the right employee. Then, in order to build the trust with Chinese employees, the foreign leaders always do so by enhancing their ability and revealing themselves. Moreover, when assigning task, these leaders are used to encourage Chinese employees' motivation of taking risk and being innovative. Further, leading from 
their heart, especially showing their care and concern, are also demonstrated by these foreign leaders as an effective way. Lastly, not only female foreign leaders but also male ones manage conflict with obliging and tender style so as to save their Chinese employees' face and create a harmonious relationship with them.

\section{Discussion}

Then combined with some of the cultural dimensions and leadership theories which have been mentioned in the literature review, the qualitative information from in-depth interview will be processed and analyzed. From the above results, we can see the five features in the expatriate foreign leaders' cross-cultural leadership style. The following part will compare these research results with some of theories and literatures that mentioned in previous section to discuss the findings.

First of all, according to the Hofstede's cultural dimension, under the influence of Confucianism for thousands of years, China gets high index in power distance and uncertainty avoidance. Thus, on one side, the leader and follower have the hierarchical relationship in which the leaders provide a less open environment and control the power of decision making when distributing work. On the other side, there are many rules to prevent uncertainty issues which hinder Chinese people's motivation of risk taking and thus reduce their creativity. This may influence Chinese leaders. But for the foreign leaders in China, they may still remain their original leadership behavior, such as decentralizing their power and encouraging employees to take risk and be innovative. This situation exactly supports the perspective which mentioned in the literature review that the leadership behavior relating to the leader's culture will be expected by the local followers [24] [25]. However, from the data collecting in interview, we can see that these Chinese cultures also have some influence on part of Western foreign leaders' leadership behaviors, when they consider about how to continue conducting their Western leadership quality well with Chinese cultural values.

From the first and second leadership behavior that we find in these foreign leaders, it obviously shows that the leader's Western leadership behaviors, such as empowerment in work assignment and encouraging risk taking, are likely to be accepted in China, only if the leaders combine them with Chinese employees' concern. In addition, as we can see from the remaining three leadership behaviors, considering about the Chinese cultural values such as creating harmonious atmosphere, saving face and indirectness which are the typical values in collectivistic and long-term relationship country, the foreign leaders decide to adapt to the followers' culture. That is, they should show more care and positive feedback in the job evaluation, tend to build personal trust with Chinese employee and manage conflicts with obliging and tender attitude. Therefore, as Dorfman, Erez and Earley, and Yukl illustrated in the cross-cultural model, the leader's competence to influence others, to a large extent, is determined by whether their practices are correspond with followers' conceptions of a ideal leader, which are largely affected by cultural differences [21] [22]. Although this result is inconsistent with the point of view presented by Ah Chong and Thomas, we should not ignore that when the 
leader's behavior was accepted as genuine by the followers [24] [44].

Moreover, based on the literature review and the result from the interview, it is not hard to find that the transformational leadership style will be effective and appropriate for the expatriate leader in the cross-cultural context since it is to influence followers from the emotional and valuable aspects. As mentioned in the literature review, there are four influential components in transformational leadership, which include idealized influence, inspirational motivation, intellectual stimulation, and individualized consideration, while the five leadership behaviors shown by these foreign leaders in this research are consistent with some of the features in transformational leadership. To start with, the leaders' leadership behaviors of empowerment, leading from heart through caring approach, and managing conflict with obliging and tender style, match the characteristic of individualized consideration in the transformational leadership style which shows that the leaders provide individual care and concern to each follower. The leaders may decentralize their authority but offer guidance so as to develop their advantages and give immediate feedback to individuals from the individualized aspect.

Secondly, from the interview, we find that, the employees need to be creative in their working process, so the foreign leaders always appreciate to provide challenge of new activity to the staff. This leadership behavior is undoubtedly consistent with the feature of inspirational motivation in transformational leadership which indicates that the leader motivates the followers to be creative and innovative by giving them challenging tasks. In this way, leaders encourage employees to find out new solutions for old issues and thus provide them a good chance to enhance their competence [45]. Then, as for the idealized influence in transformational leadership, it shows that the leader should be a role model that employees want to follow. These leaders can be trusted and admired by the employees due to their capabilities. This exactly echoes these foreign leaders' leadership behavior of building trust with Chinese employees by showing their competence. In conclusion, the five leadership behaviors conducted by these foreign leaders in China mostly correspond with the features of transformational leadership style.

\section{Implication of Research}

According to the previous findings, this study indicates that although cultural differences have some impact on the choice of leadership style, the effective leadership qualities in China for both Chinese and foreign leaders have something in common. Hence, this perspective shown in this study is consistent with the culture-universal perspective put forward by Bass and Avolio, which supports that the universal aspects of transformational leadership can offer a global application [6]:

Therefore, given the rapid development in economy and change in culture, this research indicates that it is effective for both Chinese and foreign leaders to try to mainly practice transformational leadership style and integrate this kind of leadership style with Chinese reality. That is, leaders, especially foreign leaders in China should strive to empower followers with guidance and encourage their motivation of being creative, to 
build their trust, and to give sufficient concerns and care.

If these findings can be extended, they can have the practical implication for enhancing both Chinese and foreign leaders' leadership competence across culture. On one hand, the foreign leaders can understand that they can successfully take the transformational leadership behaviors into practice in China, and they can provide an explanation about why this kind of leadership style is valuable and potentially important for the business in China. On the other hand, Chinese leaders can also make sense of how the transformational leadership style can integrate an effective leadership practices under the influence of different cultures, especially when Chinese leaders work with foreign leaders, no matter as colleagues in international organization or as cooperative partner.

\section{Limitation and Future Direction}

Clearly, it is valuable from the perspective of culture to explore a deeper understanding of challenge that the expatriate leaders face in the cross-cultural context and the effective leadership style for foreign leaders in China. Moreover, it is useful for the foreign leaders to learn how to choose a more effective leadership style in different situation. However, merely understanding of cultural influences is insufficient to achieve an effective leadership in cross-cultural context. Therefore, for the future research, first it is necessary to look into deeper area, like exploring the organizational culture rather than the national culture. Furthermore, culture is not the unique factor to influence the leadership style, so combing more leadership theories and stepping into other variables like gender, language and political influence is essential. Finally, as for the method, it suggests that both quantitative method such as doing questionnaire survey and the qualitative method like interview should combine together in order to get a more accurate and persuasive results. For example, it would be better to make a comparison between the viewpoint collecting from foreign leaders through interview and the perspective gathering from Chinese employees via survey.

\section{Conclusion}

Based on the in-depth interview analysis and discussion in the previous parts, the research question is worked out. First, it finds out that culture differences do not totally affect the foreign leaders' leadership behavior, but it will influence the expatriate their leadership style in some of the aspects. For instance, because under the influence of Chinese culture, the local followers are used to save face and create harmonious atmosphere, the foreign leaders manage conflict with tender attitude and give more care and concern. In addition, as for the relationship between leadership and cross-culture, it reveals that there are two factors to influence the leadership behavior, including the cultural values and situations. That is, the foreign leaders will vary the leadership behavior to satisfy some of the culture values that the local followers hold. Meanwhile, the leader will show different leadership behavior because of the different organizational situation. However, no matter the leaders decide to change into which leadership beha- 
viors, this research finds that in the cross-cultural context, transformational leadership will be more effective and appropriate for the foreign leaders since it is a process to influence followers from both emotional and rational aspects.

\section{References}

[1] Habib-Mintz, N. (2009) Multinational Corporations' Role in Improving Labor Standards in Developing Countries. Journal of International Business and Economy, 10, 39-58.

[2] China Daily (2005) Ninety Percent of World Top 500 Invest in China. http://www.chinadaily.com.cn/english/lt/2005-12/09/content_502103.htm

[3] Chen, G. and Liu, S. (2000) Assessing Chinese Conflict Management Styles in Joint Venture. In: Hoffer, B.L., Ed., Chinese Conflict Management in Intercultural Context. A Special Issue of Intercultural Communication Studies, 71-90.

[4] Black, J.S. and Gregersen, H.B. (1990) Expectations, Satisfaction and Intention to Leave of American Expatriate Managers in Japan. International Journal of Intercultural Relations, 14, 485-506. http://dx.doi.org/10.1016/0147-1767(90)90032-R

[5] Dorfman, P.W. and Howell, J.P. (1997) Leadership in Western and Asian Countries: Commonalities and Differences in Effective Leadership Process across Cultures. Leadership Quarterly, 8, 233-275. http://dx.doi.org/10.1016/S1048-9843(97)90003-5

[6] Bass, B.M. and Avolio, B.J. (1993) Transformational Leadership and Organizational Structure. International Journal of Public Administration Quarterly, 17, 112-121.

[7] Hofstede, G. (1993) Cultural Constraints in Management Theories. Academy of Management Executive, 7, 81-94. http://dx.doi.org/10.5465/ame.1993.9409142061

[8] Zagorsek, H., Marko, J. and Stanley, J.S. (2004) Comparing Leadership Practices between the United States, Nigeria, and Slovenia: Does Culture Matter? Cross Cultural Management, 11, 16-34. http://dx.doi.org/10.1108/13527600410797774

[9] Matveev, A.V. and Nelson, P.E. (2004) Cross Cultural Communication Competence and Multicultural Team Performance. International Journal of Cross-Cultural Management, 4, 253-270. http://dx.doi.org/10.1177/1470595804044752

[10] Chen, Y., Tjosvold, D. and Fang, S.S. (2005) Working with Foreign Managers: Conflict Management for Effective Leader Relationships in China. International Journal of Conflict Management, 16, 265-285. http://dx.doi.org/10.1108/eb022932

[11] Hallinger, P. and Heck, R. (1999) Can Leadership Enhance School Effectiveness? In: Bush, T., Bell, L., Bolam, R., Glatter, R. and Ribbins, P., Eds., Educational Management. Redefining Theory, Policy and Practice, Paul Chapman, London, 178-190. http://dx.doi.org/10.4135/9781446219676.n14

[12] Walker, A. and Dimmock, C. (Ed.) (2002) School Leadership and Administration: Adopting a Cultural Perspective. Routledge Falmer, New York.

[13] Thomas, D.C. (2008) Cross-Cultural Management: Essential Concept. 2nd Edition, Sage Publication Inc., Thousand Oaks.

[14] Gibson, C.B. (1994) The Implications of National Culture for Organization Structure: An Investigation for Three Perspectives. Advances in International Comparative Management, 9, 3-38.

[15] Walker, D. (2003) Doing Business Internationally: The Guide to Cross-Cultural Success. 2nd Edition, McGraw-Hill, New York.

[16] Hofested. G. (1991) Culture and Organizations: Software of the Mind. McGraw-Hill, London. 
[17] Hofested, G. (1984) Culture's Consequences: International Differences in Work-Related Values. 2nd Edition, Sage, Newbury Park.

[18] Dorfman, P.W. and Howell, J.P. (1988) Dimensions of National Culture and Effective Leadership Patterns: Hofstede Revisited. Advances in International Comparative Management, 3, 127-150.

[19] Maznevski, M.L. (2002) Cultural Dimensions at the Individual Level of Analysis: The Cultural Orientations Framework. International Journal of Cross-Cultural Management, 2, 275-295. http://dx.doi.org/10.1177/147059580223001

[20] Hughes, R.L., Ginnett, R.C. and Curphy, G.J. (2002) Leadership: Enhancing the Lessons of Experience. 4th Edition, McGraw-Hill/Irwin, Boston.

[21] Yukl, G. (1994) Leadership in Organizations. 3rd Edition, Prentice Hall. Upper Saddle River.

[22] Dorfman, P.W. (1996) International and Cross-Cultural Leadership. In: Punnitt, J. and Shenkar, O., Eds., Handbook for International Management Research, Blackwell, Cambridge, 276-349.

[23] Erez, M. and Earley, P.C. (1993) Culture, Self-Identity and Work. Oxford University Press, New York. http://dx.doi.org/10.1093/acprof:oso/9780195075809.001.0001

[24] Ah Chong, L.M. and Thomas, D.C. (1997) Leadership Perception in Cross-Cultural Context: Pacific Islanders and Pakeha in New Zealand. Leadership Quarterly, 8, 275-293. http://dx.doi.org/10.1016/S1048-9843(97)90004-7

[25] Peterson, M.F., Brannen, M.Y. and Simth, P.B. (1994) Janpanese and US Leadership: Issues in Current Research. Advances in International Comparative Management, 9, 57-82. http://dx.doi.org/10.1108/02621719410050219

[26] Kanter, R.M. and Corn, R.I. (1994) Do Cultural Differences Make a Business Difference? Contextual Factors Affecting Cross-Cultural Relationship Success. Journal of Management Development, 13, 5-23.

[27] Den Hartog, D.N. and Dickson, M.W. (2004) Leadership and Culture. In: Antonakis, J., Cianciolo, A.T. and Sternberg, R.J., Eds., The Nature of Leadership, Sage, London, 249-278.

[28] Dickson, M.W., Resick, C.J. and Hanges, P.L. (2006) Systematic Variations in Organizationally-Shared Prototypes of Effective Leadership Based on Organizational Form. The Leadership Quarterly, 17, 487-505. http://dx.doi.org/10.1016/j.leaqua.2006.07.005

[29] Bass, B.M. and Avolio, B.J. (1994) Improving Organizational Effectiveness through Transformational Leadership. Sage, Thousand Oaks.

[30] Hofstede, G. (2001) Culture's Consequences: Comparing Values, Behaviors, Institutions and Organizations across Nations. Sage, Thousand Oaks.

[31] Den Hartog, D.N., House, R.J., Hanges, P.J., Ruiz-Quintanilla, S.A., Dorfman, P.W. and GLOBE Associates (1999) Culture Specific and Cross-Culturally Generalizable Implicit Leadership Theories: Are Attributes of Charismatic/Transformational Leadership Universally Endorsed? The Leadership Quarterly, 10, 219-256.

http://dx.doi.org/10.1016/S1048-9843(99)00018-1

[32] Posner, B.Z. and Harder, J.W. (2002) The Proactive Personality, Leadership, Gender and National Culture. Annual Conference of the Western Academy of Management, Santa Fe, March 2002.

[33] Spreitzer, G.M., Perttula, K.H. and Xin, K. (2005) Traditionality Matters: An Examination of the Effectiveness of Transformational Leadership in the United States and Taiwan. Journal of Organizational Behavior, 26, 205-227. http://dx.doi.org/10.1002/job.315

[34] Shao, L. and Webber, S. (2006) A Cross-Cultural Test of "Five-Factor Model of Personality 
and Transformational Leadership". Journal of Business Research, 59, 936-944.

http://dx.doi.org/10.1016/j.jbusres.2006.02.005

[35] Jung, D., Yammarino, F.J. and Lee, J.K. (2009) Moderating Role of Subordinates' Attitudes on Transformational Leadership and Effectiveness: A Multi-Cultural and Multi-Level Perspective. The Leadership Quarterly, 20, 586-603.

http://dx.doi.org/10.1016/j.leaqua.2009.04.011

[36] Bass, B.M. (1990) Bass and Stogdill's Handbook of Leadership: Theory, Research, and Management Applications. 3rd Edition, Free Press, New York.

[37] Ergeneli, A., Gohar, R. and Temirbekova, Z. (2007) Transformational Leadership: Its Relationship to Culture Value Dimensions. International Journal of Intercultural Relations, 31, 703-724. http://dx.doi.org/10.1016/j.ijintrel.2007.07.003

[38] Ghauri, P. and Gronhaug, K. (2010) Research Method in Business Studies. 4th Edition, Pearson, London.

[39] Arksey, H. and Knight, P. (1999) Interviewing for Social Scientists. Sage, London. http://dx.doi.org/10.4135/9781849209335

[40] Easterby-Smith, M., Thorpe, R. and Lowe, A. (1991) Management Research: An Introduction. Sage, London.

[41] Putnam, L. and Wilson, C. (1982) Communication Strategies in Organizational Conflict: Reliability and Validity of a Measurement. In: Burgoon, M., Ed., Communication Yearbook, Sage, Beverly Hills.

[42] Neuman, W.L. (1997) Social Research Methods: Qualitative and Quantitative Approaches. 3rd Edition, Allyn and Bacon, Boston.

[43] Mostyn, B. (1985) The Content Analysis of Qualitative Research Data: A Dynamic Approach. In: Brenner, M., Brown, J. and Canter, D., Eds., The Research Interview. Uses and Approaches, Academic Press, London.

[44] Thomas, D.C. and Ravlin, E.C. (1995) Responses of Employees to Cultural Adaptation by a Foreign Manager. Journal of Applied Psychology, 80, 133-146.

http://dx.doi.org/10.1037/0021-9010.80.1.133

[45] Diaz-Saenz, H.R. (2011) Transformational Leadership. In: Bryman, A., Collinson, D., Grint, K., Jackson, B. and Uhl-Bien, M., Eds., The SAGE Handbook of Leadership, Sage, Thousand Oaks, 299-310. 


\section{Appendix 1}

He interview will take approximately 45 minutes of your time. Your responses will be used to write an explorative research. Only researcher will have access to the information you provide me in the notes, tapes and the paper written of the interview. Afterwards, all notes will be destroyed and tapes erased. I will keep a copy of the paper on file but will treat it with the strictest confidentiality.

If you take part in the study, you have the right to:

1. Refuse to answer any particular question, and to withdraw from the study "state a withdrawal date".

2. Ask any further questions about the study that occurs to you during your participation.

Be given access to a summary of the findings from the study when it is concluded.

\section{Interview Question}

1. How long have you held your leadership position in your organization?

2. What are your responsibilities in workplace? Please tell me about your main items that you do every day in this organization.

3. What major changes did you make after you got this position?

4. In your work, you have to communicate with the Chinese employees and the foreign ones. What are the differences?

5. Do you think yourself a good role model for your Chinese employees? Why?

6. When you communicate with Chinese employees, what are the communication barriers and challenges? How do you deal with them?

7. How do you deal with conflict with your native colleague? Can you give an example?

8. Do you treat all your members the same, or do you treat them different based on their traits or something else?

9. How do you distribute the work to your Chinese employees? Are there any difficulties? How do you deal with it?

10. Do you support your member to try new approaches when you distribute work to them? If do so, how do you support them?

11. How do you motive your members to have more commitment and shared vision in your organization?

12. Do you give feedback to your colleagues? If so, please describe how do you give feedback to them?

13. How do the different cultural values between Chinese employees and yours affect your leadership? 
Submit or recommend next manuscript to SCIRP and we will provide best service for you:

Accepting pre-submission inquiries through Email, Facebook, LinkedIn, Twitter, etc. A wide selection of journals (inclusive of 9 subjects, more than 200 journals)

Providing 24-hour high-quality service

User-friendly online submission system

Fair and swift peer-review system

Efficient typesetting and proofreading procedure

Display of the result of downloads and visits, as well as the number of cited articles

Maximum dissemination of your research work

Submit your manuscript at: http://papersubmission.scirp.org/

Or contact jss@scirp.org 